\title{
Study of Activated Carbons by Pyrolysis of Mangifera Indica Seed (Mango) in Presence of Sodium and Potassium Hydroxide
}

\author{
J.C.MORENO-PIRAJÁN ${ }^{\mathrm{a}^{*}}$ and L. GIRALDO ${ }^{\mathrm{b}}$ \\ ${ }^{a}$ Departamento de Química, Facultad de Ciencias, Universidad de Los Andes \\ Grupo de Investigación en Sólidos Porosos y Calorimetría, Bogotá, Colombia. \\ ${ }^{\mathrm{b}}$ Departamento de Química, \\ Universidad Nacional de Colombia, Bogotá, Colombia \\ jumoreno@uniandes.edu.co
}

Received 20 August 2011; Accepted 27 October 2011

\begin{abstract}
Activated carbons (ACs) were prepared by pyrolysis of seeds mango in presence of sodium and potassium hydroxide (chemical activities). Seeds mango from Colombian Mango cultives were impregnated with aqueous solutions of $\mathrm{NaOH}$ and $\mathrm{KOH}$ following a variant of the incipient wetness method. Different concentrations were used to produce impregnation ratios of 3:1 (weight terms). Activation was carried out under argon flow by heating to $823 \mathrm{~K}$ with $1 \mathrm{~h}$ soaking time. The porous texture of the obtained ACs was characterized by physical adsorptions of $\mathrm{N}_{2}$ at $77 \mathrm{~K}$ and $\mathrm{CO}_{2}$ at $273 \mathrm{~K}$. The impregnation ration and hydroxide type had a strong influence on the pore structure of these ACs, which could be easily controlled by simply varying the proportion of the hydroxides used in the activation. Thus, the development of porosity for precursors with low structural order (high reactivity) is better with $\mathrm{NaOH}$ than $\mathrm{KOH}$, whereas the opposite is observed for the highly ordered ones. Variable adsorption capacities and porosity distributions can be achieved depending on the activating agent selected. In general, $\mathrm{KOH}$ produces activated carbons with narrower micropore distributions than those prepared by $\mathrm{NaOH}$.
\end{abstract}

Keywords: Seeds mango, Adsorption, Surface area, Activated carbon, Activation with hydroxides.

\section{Introduction}

Chemical activation is one of the possible methods to produce activated carbons (ACs) ${ }^{1-6}$. It involves pyrolyzing the feedstock in presence of a chemical activating agent such as $\mathrm{H}_{3} \mathrm{PO}_{4}$, $\mathrm{ZnCl}_{2}, \mathrm{H}_{2} \mathrm{SO}_{4}$ etc. Almost any lignocellulosic material can be used as precursors for the production of activated carbons. The use of a suitable precursor is mainly conditioned by its availability and cost, although it also depends on the main applications of the manufactured carbon and the type of installation available. Activated carbon production from coal is an old process. Due to the high cost in the production of activated carbon from coal, the use of lignocellulosic materials as precursor for the production of activated carbons has attracted 
much attention. The idea is to find cheap and efficient precursor for the production of activated carbon. Activated carbon can be produced from all carbon containing lignocellulosic materials i.e. $\operatorname{lignin}^{7}$, macro-algal $^{8}$, defective coffee press cake ${ }^{9}$, palm shell ${ }^{10}$, rice husk ${ }^{11}$ wastes of vegetable origin (e.g. nutshells, fruit stones $)^{12,13}$. There are two processes for preparation of activated carbon: chemical activation and physical activation. Chemical activation is known as a single step method of preparation of activated carbon in the presence of chemical agents. Physical activation involves carbonization of a carbonaceous materials followed by activation of the resulting char in the presence of activating agents such as $\mathrm{CO}_{2}$ or steam. The chemical activation usually takes place at a temperature lower than that used in physical activation, therefore it can improve the pore development in the carbon structure because the effect of chemicals. The carbon yields of chemical activation are higher than physical one ${ }^{14}$.

Mango as fruit is one of the most important foods in Colombia, an agricultural country. Seeds Mango is one of the primary fruits in our country and usually used for traditional food fruits, cake, etc. The mango production in Colombia is very huge and only small amounts are utilized by traditional food industries, and the rest are used as the raw material for mango candy industries. Seed mango produces a large amount of solid wastes (seeds mango), and direct discharge of this solid wastes will cause the environmental problems. Here we report on the porous texture characteristics of ACs prepared by $\mathrm{NaOH}$ and $\mathrm{KOH}$ activation of seeds mango. These constitute a by-product from mango processing following harvest with few practical applications and whose uncontrolled spill (e.g. in rivers) causes some environmental concern. In fact, applications of seeds are limited to use as fuel or as feedstock to obtain food for animal. We will show that carbon adsorbents with high surface areas and pore volumes can be obtained from this material, and that development of the porous structure can be modulated by of the hydroxides type use in the activation chemical. Prior to the use, the seeds mango was repeatedly washed with distilled water in order to remove fibres and other inorganic impurities, then oven-dried for $48 \mathrm{~h}$ at $393 \mathrm{~K}$ to reduce the moisture content.

\section{Experimental}

Seeds from Colombian mango were impregnated with aqueous solutions of sodium and potassium hydroxides following with a 3:1 ratios of the incipient wetness method; similar cases have been described in literature ${ }^{15,16}$. This consists of adding dropwise (while stirring the solid, to facilitate homogeneous absorption of liquid) the amount of aqueous solution (4.0 $\mathrm{mL} \mathrm{g}^{-1}$ seeds mango) necessary to produce swelling until incipient wetness. Two different hydroxides alkaline at 3:1 relation in weight are used as impregnant agent in the activation process using seeds mango $(\mathrm{NaOH}$ and $\mathrm{KOH})$. After impregnation, the samples were dried for $12 \mathrm{~h}$ at $383 \mathrm{~K}$ in air. Pyrolysis treatments (activations) were carried out in a vertical tubular reactor made of quartz in furnace Carbolite ${ }^{\mathrm{TM}}$, using in all cases $45 \mathrm{~g}$ of impregnated and dried material. All treatments were done at a constant heating rate of $5 \mathrm{~K}$ $\mathrm{min}^{-1}$ and with an argon (99.999\% pure) flow of $5 \mathrm{STP} \mathrm{cm}^{3} \mathrm{~min}^{-1}$, which was kept during heating and cooling. An activation temperature of $923 \mathrm{~K}$ and $1123 \mathrm{~K}$ and a soaking time of $8 \mathrm{~h}$ were used. After cooling the solid pyrolysis residue to room temperature it was washed with milli-Q distilled water until lowering the conductivity of the washing liquids to $<5 \mu \mathrm{S} \mathrm{cm}^{-1}$ (measured with a $\mathrm{pH} /$ conductivity meter HP, model MARK 602). The resulting ACs were dried at $383 \mathrm{~K}$ for $48 \mathrm{~h}$ in a vacuum furnace. The activated carbon synthesized area labeled: CMK923 and CMK1123 (for potassium); CMNa923 and CMNa1123 (for sodium). The porous texture of ACs was characterized by physical adsorption of nitrogen at $77 \mathrm{~K}$ (using an automatic volumetric adsorption apparatus, AUTOSORB 3B from Quantachrome Corporation) and carbon dioxide at $273 \mathrm{~K}$ (using a automatic volumetric adsorption 
apparatus, Autosorb 3B from Quantachrome Corporation, USA). In either case the samples were degassed overnight at $573 \mathrm{~K}$ before every adsorption measurement. Gases used had minimum purities of $99.999 \%\left(\mathrm{~N}_{2}\right)$ and $99.98 \%\left(\mathrm{CO}_{2}\right) . \mathrm{N}_{2}$ adsorption data were analyzed by means of the BET and Dubinin-Radushkevich (DR) equations, the $\alpha_{\mathrm{S}}$ method (using Spheron-6 carbon black as reference material) and the density functional theory (DFT). $\mathrm{CO}_{2}$ adsorption data were analyzed by the Dubinin-Radushkevich-Kaganer (DRK) equation.

\section{Results and Discussion}

The isotherms are type Ia for the AC activated with potassium hydroxide, CMK923 (typical of microporous materials where micropore filling may take place by primary filling at very low $\left.\mathrm{p} / \mathrm{p}_{\mathrm{o}}\right)^{16}$ with a small development of mesopores, and type Ib for CMK1123 (typical of microporous materials where micropore filling may take place by co-operative filling in wider micropores over a range of higher $\mathrm{p} / \mathrm{p}_{\mathrm{o}}$ than in type Ia) ${ }^{16}$.

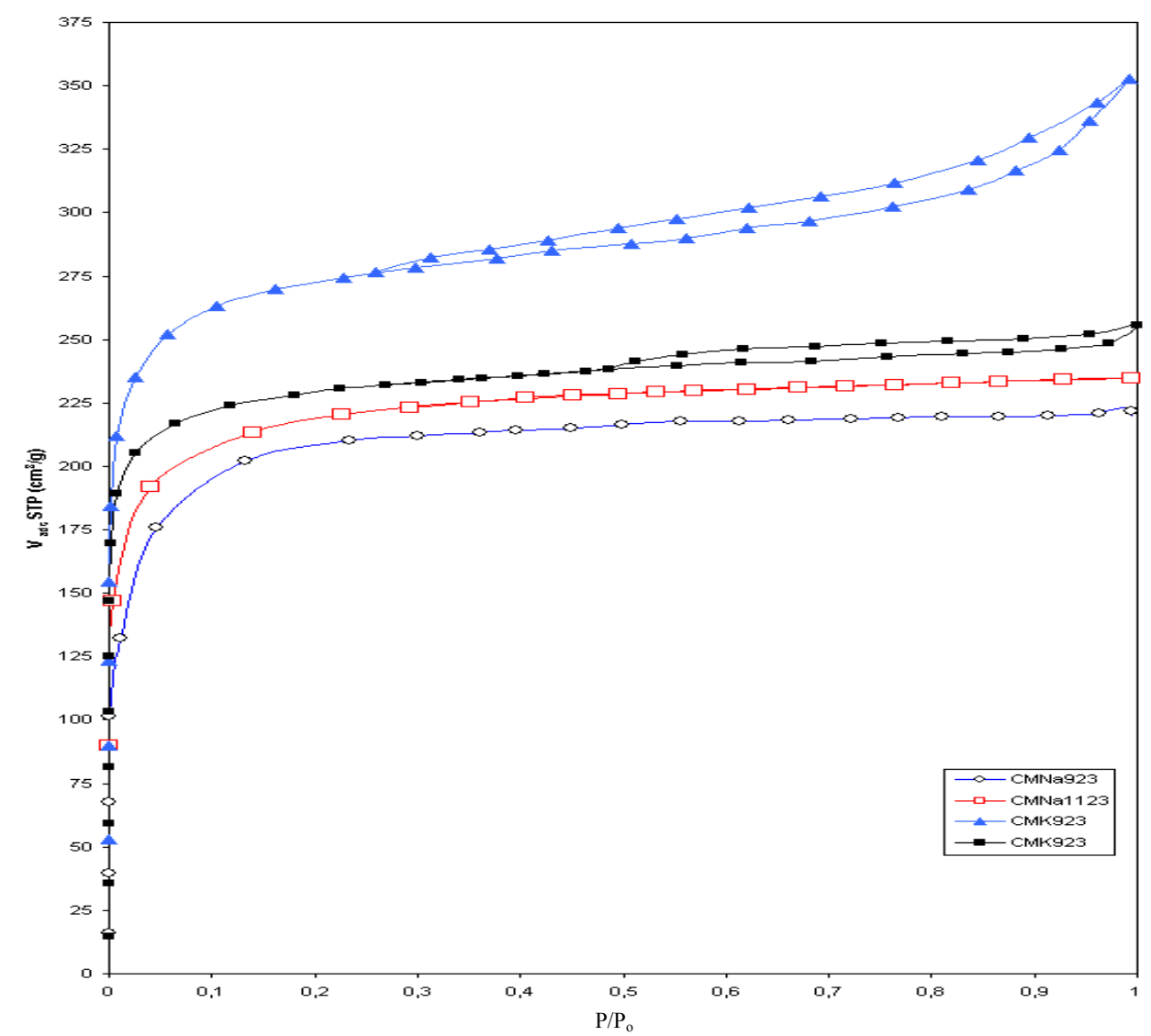

Figure 1. Shows adsorption-desorption isotherms of $\mathrm{N}_{2}$ at $77 \mathrm{~K}$ on ACs from seeds mango impregnated with $\mathrm{NaOH}$ and $\mathrm{KOH}$ at $923 \mathrm{~K}$ and $1123 \mathrm{~K}$.

The AC prepared by impregnation with sodium hydroxide gives a type Ib isotherm, but in this case a plateau is clearly reached, indicating widening of pores; this isotherm not exhibits hysteresis loop. Similar evolutions from type I to type II isotherms with used of these type hydroxides, but with others materials are reported have been reported by other authors $^{17-21}$. 
Table 1 reports textural parameters deduced from $\mathrm{N}_{2}$ and $\mathrm{CO}_{2}$ adsorption isotherms. The BET $\left(S_{\mathrm{BET}}\right)$ and micropore $\left[\mathrm{S}_{\text {microp. }}\left(\mathrm{DR}, \mathrm{N}_{2}\right)\right]$ surface areas increase with increasing of temperature and are major with $\mathrm{NaOH}$. The micropore surface areas deduced from $\mathrm{CO}_{2}$ isotherms $\left[\mathrm{S}_{\text {microp. }}\left(\mathrm{DRK}, \mathrm{CO}_{2}\right)\right]$ go through a maximum with the sample CMNa1123. The external surface area $\left[S_{\text {ext }}\left(\alpha_{S}, N_{2}\right)\right]$ also increases with increasing of temperature and with the sodium hydroxide, slightly in both cases.

Table 1. Textural parameters deduced from $\mathrm{N}_{2}$ adsorption at $77 \mathrm{~K}$ and $\mathrm{CO}_{2}$ adsorption at $273 \mathrm{~K}$ on ACs prepared at different temperatures and different hydroxides.

\begin{tabular}{|c|c|c|c|c|c|c|c|c|c|c|}
\hline $\begin{array}{l}\text { SAM } \\
\text { PLE }\end{array}$ & $\mathrm{N}_{2}$ & & & & & & & & & $\mathrm{CO}_{2}$ \\
\hline & SBET & Sext. & $\mathrm{Vp}$ & $\begin{array}{c}\text { DFT- } \\
\text { method } \\
\text { Vmp. }\end{array}$ & Vmp. & Vmp. & $\begin{array}{c}\text { DR- } \\
\text { method } \\
\text { Smicrop. }\end{array}$ & Vmp & $\begin{array}{c}\text { DRK- } \\
\text { method } \\
\text { Smicrop. }\end{array}$ & Vmp \\
\hline $\begin{array}{c}\text { CMK- } \\
923\end{array}$ & 1437 & 10 & 0.77 & 0.06 & 0.76 & 0.03 & 1400 & 0.80 & 1454 & 0.71 \\
\hline $\begin{array}{c}\text { CMK- } \\
1123\end{array}$ & 1500 & 17 & 0.85 & 0.09 & 0.83 & 0.04 & 1487 & 0.89 & 1365 & 0.79 \\
\hline $\begin{array}{c}\text { CMNa- } \\
923\end{array}$ & 1780 & 26 & 0.97 & 0.10 & 0.93 & 0.07 & 1776 & 1,02 & 1465 & 0.90 \\
\hline $\begin{array}{c}\text { CMNa- } \\
1123\end{array}$ & 1987 & 35 & 1.18 & 0.13 & 1.09 & 0.09 & 1960 & 1,21 & 1675 & 1.04 \\
\hline
\end{tabular}

Surface areas in $\mathrm{m}^{2} \mathrm{~g}^{-1}$; pore volumes in $\mathrm{cm}^{3} \mathrm{~g}^{-1}$.

The total pore volume, $V_{\mathrm{p}}\left(\mathrm{N}_{2}\right)$ (calculated from $\mathrm{N}_{2}$ adsorption data as volume of liquid $\mathrm{N}_{2}$ at a relative pressure of 0.975 ) increases continuously with increasing of temperature and with the change of alkaline hydroxide; is major with the sodium hydroxide that with the the potassium as does the mesopore volume, $V_{\mathrm{mp}}\left(\mathrm{DFT}, \mathrm{N}_{2}\right.$ ) (volume of pores with widths between 2 and $50 \mathrm{~nm}$ ). The ultramicropore volume, $\mathrm{V}_{\text {umicrop. }}\left(\mathrm{DFT}, \mathrm{N}_{2}\right.$ ) (volume corresponding to pores of width $<0.7 \mathrm{~nm}$ ) follows the same trend. This behavior shows a consistent and uniform with the material behavior we have seen with other materials we are studying in our laboratory.

Let us examine now the variation of the micropore volume as a function of temperature and with treatment if sodium and potassium hydroxides. Parameters such as $V_{\text {micropo. }}$ (DRK, $\mathrm{CO}_{2}$ )] and $V_{\text {micropo. }}\left(\mathrm{DFT}, \mathrm{N}_{2}\right.$ ) (the latter being calculated as the volume of pores of width $<2$ $\mathrm{nm})$ go through a maximum with the sample $\mathrm{CHNa1123}$. The parameter alternative $\mathrm{V}_{\text {microp. }}$. (DR, $\mathrm{N}_{2}$ ) increases again with increasing of temperature over the hydroxides studied. The different in the atomic diameters between ions sodium and potassium have generated this type different in the characteristics texturals of activated carbon obtained seeds mango. $V_{\text {micropo. }}\left(\mathrm{DRK}, \mathrm{CO}_{2}\right)$ is always smaller than $V_{\text {micropo. }}\left(\mathrm{DFT}, \mathrm{N}_{2}\right)$ and $V_{\text {micropo. }}\left(\mathrm{DR}, \mathrm{N}_{2}\right)$, this being attributable to the presence of wide micropores that are not filled with $\mathrm{CO}_{2}$ at the low relative pressures $(<0.03)$ attained at $273 \mathrm{~K}$; it is well known that, under these conditions, $\mathrm{CO}_{2}$ only measures narrow microporosity ${ }^{11}$. The differences between $V_{\text {micropo. }}\left(\mathrm{DFT}, \mathrm{N}_{2}\right.$ ) and $V_{\text {micropo. }}\left(\mathrm{DR}, \mathrm{N}_{2}\right.$ ) are ascribable to the artifactual minimum around $1 \mathrm{~nm}$ that arises systematically in DFT calculations. This minimum, introduced by modeling assumptions ${ }^{12,13}$, certainly contributes to underestimate the micropore volume as calculated by this method.

Figure 2 shows pore size distributions (PSDs) calculated by means of the DFT method from $\mathrm{N}_{2}$ adsorption data. Values below $1 \mathrm{~nm}$ can be noticed in all cases. The width of the distribution increases with the samples obtained with sodium hydroxides. The AC prepared with sodium hydroxide at $1123 \mathrm{~K}$ exhibits a maximum at $0.50 \mathrm{~nm}$ and $1.0 \mathrm{~nm}$, which 
becomes displaced towards larger pore sizes $(2.0-3.0 \mathrm{~nm})$ with sodium hydroxide at $923 \mathrm{~K}$. For these samples this is the maximum. An increase in the pore volume and a displacement towards narrow pore sizes can be clearly noticed of according the impregnation type of hydroxides. Finally, a slight development of mesopore volume also increases with the treatment of potassium hydroxide.

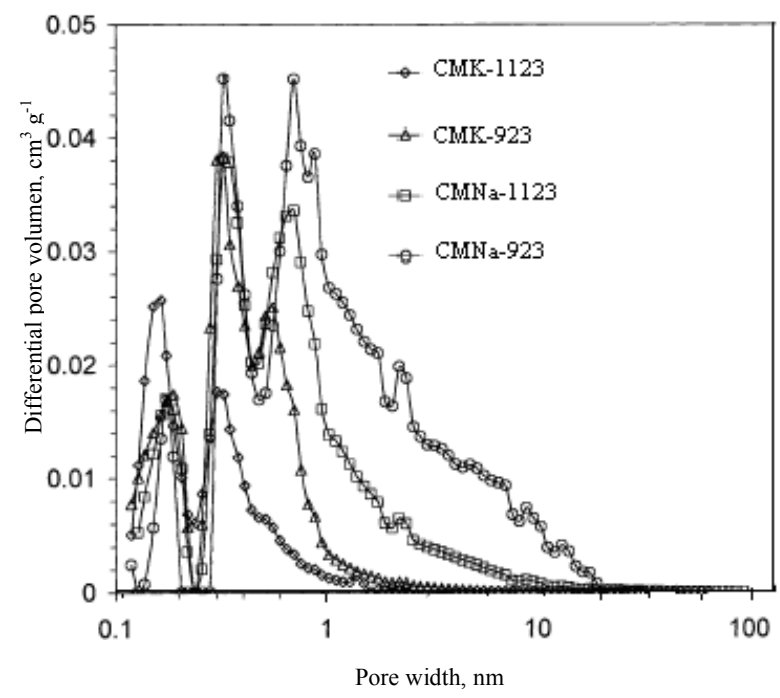

Figure 2. PSDs obtained by applying the DFT theory to $\mathrm{N}_{2}$ adsorption data at $77 \mathrm{~K}$.

From the above results one can deduce that the ACs obtained at the studied temperatures and the hydroxides type used as impregnant agent are essentially microporous. As the temperature increases, pores with wide range of sizes are developed so that with activated carbons obtained with sodium hydroxide present slight mesoporosity was higher in activated carbon obtained with sodium hydroxide as impregnant agent. Similar effects but with using other activated carbon of different precursors' nature on porosity development have been reported ${ }^{17-22}$. It is generally accepted that the porosity is generated by effect of the temperature remaining intercalated in the internal structure of lignocellulosic materials. As the types of hydroxides are changed, the volume filled by these and various polyphosphates will increase, resulting in larger pore volume and pore size.

\section{Conclusion}

In summary, pyrolysis of seeds mango impregnated with sodium and potassium hydroxides produces materials with a well-developed pore structure and very high adsorption capacities, making possible to attain surface areas as very high as $1987 \mathrm{~m}^{2} \mathrm{~g}^{-1}$ and pore volumes as large as $1.18 \mathrm{~cm}^{3} \mathrm{~g}^{-1}$. The type of hydroxide and temperature in the impregnation ratio studied has a strong influence on the pore structure of these ACs, which can be easily controlled by simply varying this variables used in the activation. Thus, $\mathrm{KOH}$ produces activated carbons with narrower micropore distributions than those prepared by $\mathrm{NaOH}$. At intermediate impregnation ratios, ACs with wide PSDs (from micropores to mesopores slight) are obtained. 


\section{Acknowledgment}

The authors would like to thank the Departments of Chemistry Departments at the Universidad Nacional de Colombia and Universidad de Los Andes (Colombia) and the Master Agreement established between these two institutions. A special thanks to the Fondo Especial de Investigaciones de la Facultad de Ciencias de la Universidad de Los Andes (Colombia) for its financing.

\section{References}

1. Suárez-García F, Martínez-Alonso A and Tascón J M D, Carbon, 2001, 39, 1111-1115.

2. Molina-Sabio M, Rodríguez-Reinoso F, Caturla F and Sellés M J, Carbon, 1995, 33, pp. 1105-1113.

3. Philip C A and Girgis B S, J Chem Tech Biotechnol., 1996, 67, 248-254.

4. Jagtoyen M and Derbyshire F, Carbon, 1998, 36, 1085-1097.

5. Girgis B S and Ishak M F, Mater Lett., 1999, 39, 107-114.

6. Laine J, Calafat J and Labady M, Carbon, 1989, 25, 191-195.

7. Cotoruelo L M, Marqués M D, Rodríguez-Mirasol J, Rodríguez $\mathrm{J} \mathrm{J}$ and Cordero $\mathrm{T}, J$ Colloid Interf Sci., 2009, 332, 39-45.

8. Aravindhan R, Rao J R and Nair B U, J Hazard Mater., 2009, 162, 688-694.

9 Nunes A A, Franca A S and Oliveira L S, Bioresour Technol., 2009, 100, 1786-1792.

10 Sumathi S, Bhatia S, Lee K T and Mohamed A R, Bioresour Technol., 2009, 100, 1614-1621.

11. Kumagai S, Noguchi Y, Kurimoto Y and Takeda K, Waste Manage., 2007, 27, 554-561.

12. Aygun A, Yenisoy-Karakas S and Duman L, Micropor Mesopor Mater., 2003, 66, 189-195.

13. Ucar S, Erdem M, Tay T and Karago“z S, Appl Surface Sci., 2009, 255(11), 8890-8896.

14. Sudaryanto Y, Hartono S B, Irawaty W, Hindarso H and Ismadji S, Biores Technol., 2006, 97, 734-739.

15. Suárez-García F, Martínez-Alonso A and Tascón J M D, J Anal Appl Pyrol., 2002, 62, 93-109.

16. Baquero MC, Giraldo L, Moreno J C, Suárez-García F, Martínez-Alonso A and Tascón J M D, J Anal Appl Pyrol., 2003, 70, 779-784.

17. Lillo-Ródenas M A, Carratalá-Abril J, Cazorla-Amorós D and Linares-Solano A, Fuel Process Technol., 2002, 331, 77-78.

18. Maciá-Agulló J A, Moore B C, Cazorla-Amorós D and Linares-Solano A, Carbon, 2004, 42, 1367-1372.

19. Guo Y, Yu K, Wang Z and Xu H, Carbon, 2003, 41, 1645-1651.

20. Perrin A, Celzard A, Albiniak A, Kaczmarczyk J, Marécheé J F and Furdin G, Carbon, 2004, 42, 2855-28862.

21. Lillo-Ródenas MA, Juan-Juan J, Cazorla-Amorós D and Linares-Solano A, Carbon, 2004, 42, 1371-1382.

22. Cazorla-Amorós, Alcañíz-Monje J, Casa-Lillo M A and Linares-Solano A, Langmuir 1998, 14, 4589-4593. 


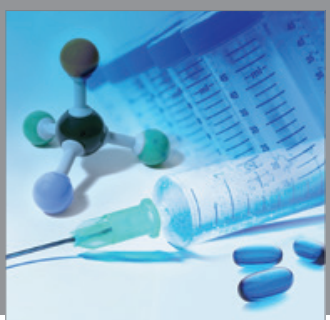

International Journal of

Medicinal Chemistry

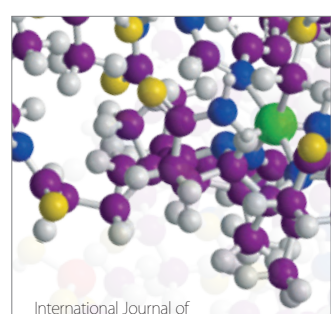

Carbohydrate Chemistry

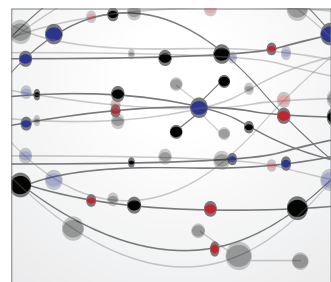

The Scientific World Journal
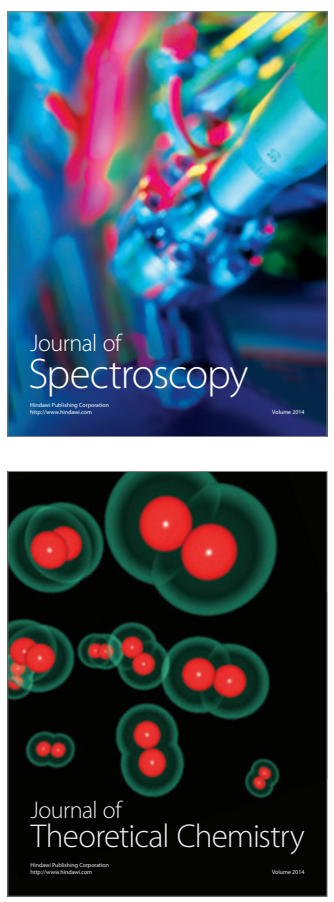
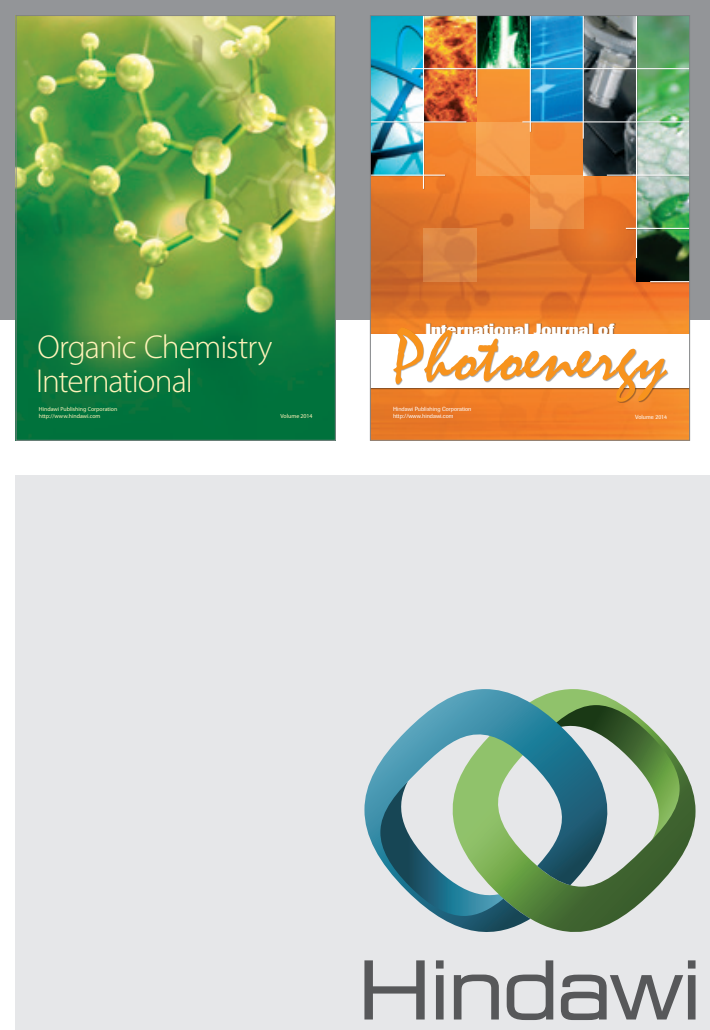

Submit your manuscripts at

http://www.hindawi.com
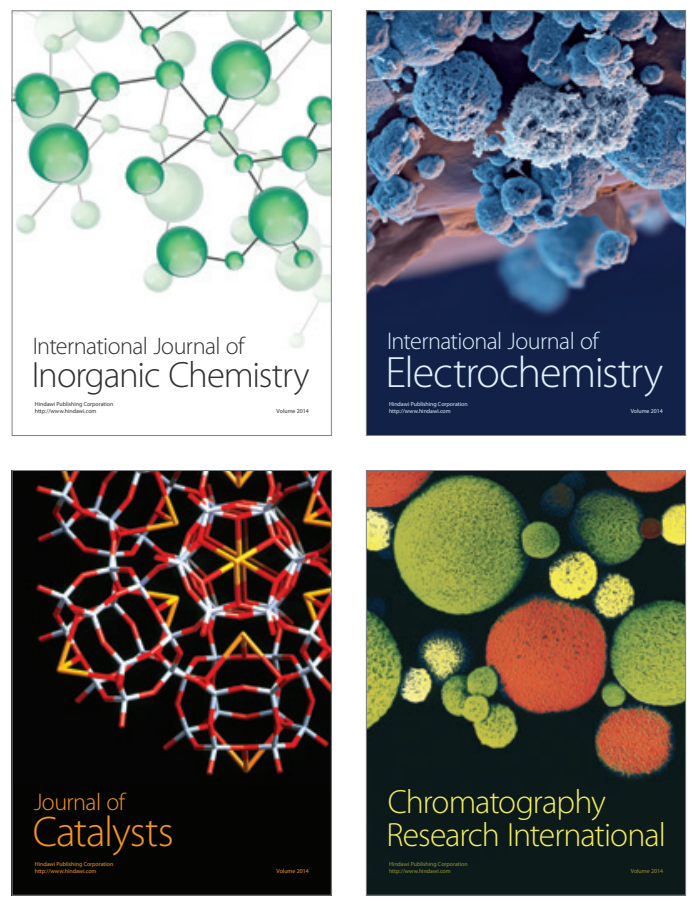
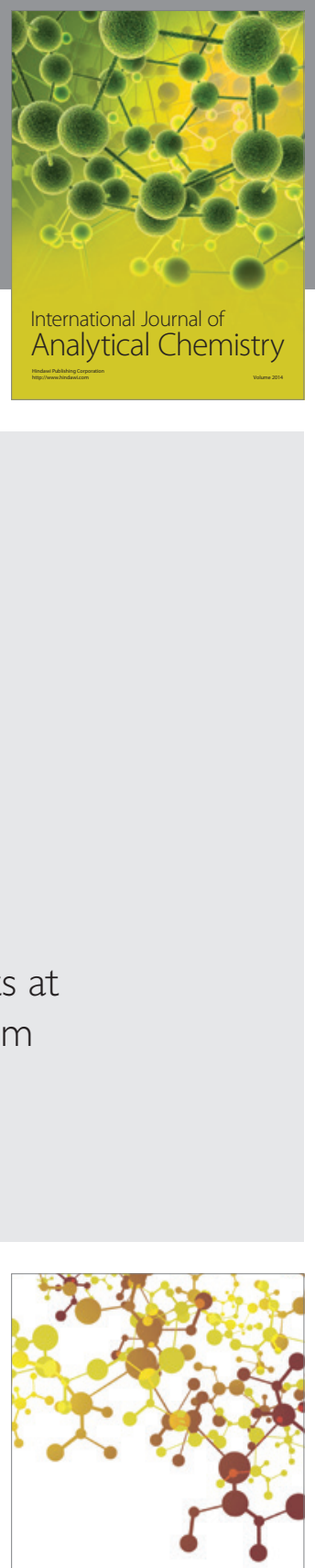

Journal of

Applied Chemistry
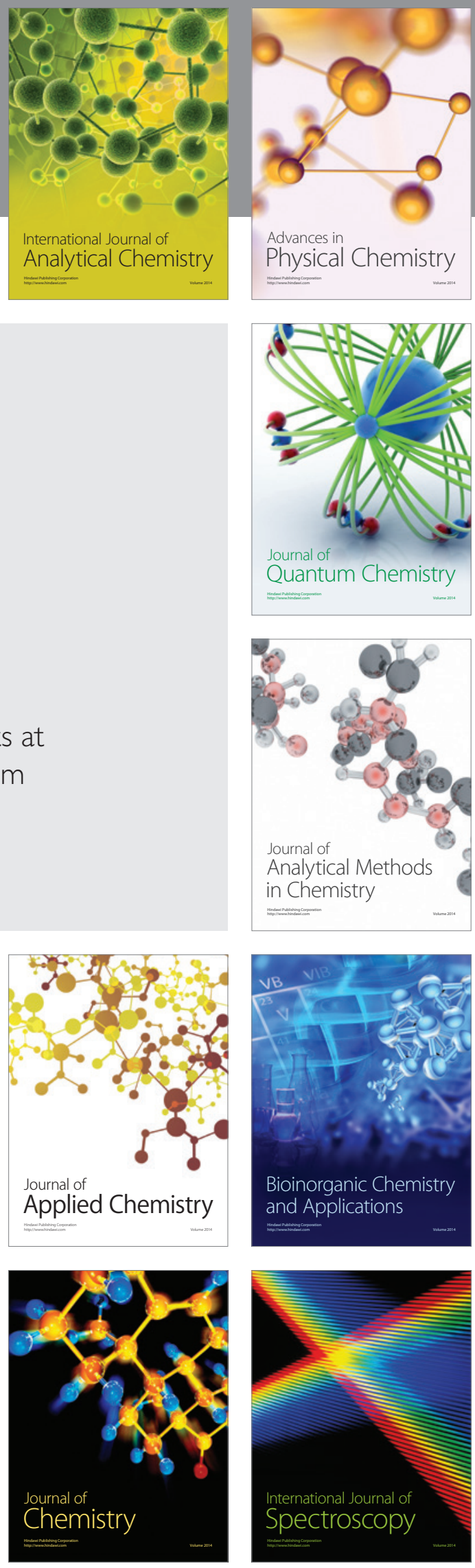